The final, definitive version of this paper has been published in Journal of

Psychopharmacology, vol. 23 no. 5, June 2009 by SAGE Publications Ltd. All rights reserved. (C) SAGE Publications Ltd. 


\title{
Reduced memory and attention performance in a population-based sample of young adults with a moderate lifetime use of cannabis, ecstasy and alcohol
}

\author{
F. Indlekofer, Department of Psychiatry and Psychotherapy, Ludwig Maximilian University, Munich, \\ Germany. \\ M. Piechatzek, Department of Psychiatry and Psychotherapy, Ludwig Maximilian University, Munich, \\ Germany. \\ M. Daamen, Department of Psychiatry and Psychotherapy, Friedrich Wilhelm University, Bonn, \\ Germany. \\ C. Glasmacher, Department of Psychiatry and Psychotherapy, Friedrich Wilhelm University, Bonn, \\ Germany. \\ R. Lieb, Max Planck Institute for Psychiatry, Munich, Germany. \\ H. Pfister, Max Planck Institute for Psychiatry, Munich, Germany. \\ O. Tucha, School of Psychology, University of Plymouth, Plymouth, Devon, UK. \\ K.W. Lange, Department of Experimental Psychology, University of Regensburg, Regensburg, \\ Germany. \\ H.U. Wittchen, Max Planck Institute for Psychiatry, Munich, Germany; Department of Psychiatry and \\ Psychotherapy, University of Dresden, Dresden, Germany. \\ C.G. Schütz, Department of Psychiatry and Psychotherapy, Friedrich Wilhelm University, Bonn, \\ Germany; Institute of Mental Health, University of British Columbia, Vancouver, BC, Canada.
}

\begin{abstract}
Regular use of illegal drugs is suspected to cause cognitive impairments. Two substances have received heightened attention: 3,4- methylenedioxymethamphetamine (MDMA or 'ecstasy') and $\delta$ - 9tetrahydrocannabinol (THC or 'cannabis'). Preclinical evidence, as well as human studies examining regular ecstasy consumers, indicated that ecstasy use may have negative effects on learning, verbal memory and complex attentional functions. Cannabis has also been linked to symptoms of inattention and deficits in learning and memory. Most of the published studies in this field of research recruited participants by means of newspaper advertisements or by using word-of-mouth strategies. Because participants were usually aware that their drug use was critical to the research design, this awareness may have caused selection bias or created expectation effects. Focussing on attention and memory, this study aimed to assess cognitive functioning in a community-based representative sample that was derived from a large-scale epidemiological study. Available data concerning drug use history allowed sampling of subjects with varying degrees of lifetime drug experiences. Cognitive functioning was examined in 284 young participants, between 22 and 34 years. In general, their lifetime drug experience was moderate. Participants completed a neuropsychological test battery, including measures for verbal learning, memory and various attentional functions. Linear regression analysis was performed to investigate the relationship between cognitive functioning and lifetime experience of drug use. Ecstasy and cannabis use were significantly related to poorer episodic memory function in a dose-related manner. For attentional measures, decrements of small effect sizes were found. Error measures in tonic and phasic alertness tasks, selective attention task and vigilance showed small but significant effects, suggesting a stronger tendency to experience lapses of attention. No indication for differences in reaction time was found. The results are consistent with decrements of memory and attentional performance described in previous studies. These effects are relatively small; however, it must be kept in mind that this study focussed on assessing young adults with moderate drug use from a population-based study.
\end{abstract}

Key words alcohol; alertness; cannabis; divided attention; ecstasy; flexibility; learning; memory; selective attention; vigilance 


\section{Introduction}

3,4-Methylenedioxymethamphetamine (MDMA or 'ecstasy') is one of the most frequently consumed illegal substances among adolescents and young adults. Because of its combination of stimulant, euphoric, anxiolytic and 'entactogenic' effects (i.e., feelings of closeness and reduced inhibition in contact with others), it has become quite popular among attendees of rave and techno parties (Dumont and Verkes, 2006). Recent epidemiological surveys in the United States and Europe showed lifetime prevalence in young adults (18-30 years) between $4.7 \%$ and $13.0 \%$ (Strote, et al., 2002; von Sydow, et al., 2002). In approximately $97.0 \%$ of cases, ecstasy users report additional use of other drugs (Schuster, et al., 1998), with cannabis, stimulants and alcohol being the most prevalent.

The pharmacological effects of ecstasy are mainly mediated by its facilitating effects on the cellular release and reuptake inhibition of serotonin (5-HT: reviewed in Green, et al., 2003). Reports of possible neurotoxic processes in animal models (Ricaurte, et al., 2000) and in humans (McCann, et al., 1998, 2000; Reneman, et al., 2001) have spurred increased research interest. Because the precise mechanisms and the extent of neurotoxicity have not been entirely elucidated, it is still a topic of intense debate (Morton, 2005; Gouzoulis- Mayfrank and Daumann, 2006). Neurotoxic effects cannot be studied experimentally in human subjects; hence, researchers have to rely on naturalistic samples of ecstasy users, and use indirect measures for the integrity of brain function. Useful techniques include neuroimaging methods, such as ligandpositron emission tomography (PET) (Reneman, et al., 2005), and neuropsychological assessments of cognitive functions. In recent years, the relationship between drug use, especially of illegal drugs, and cognitive functioning has received heightened attention (Rogers and Robbins, 2001), particularly in regard to ecstasy. The most consistent neuropsychological findings in heavy ecstasy users are subtle deficits in verbal learning and memory. Relative to nondrug controls and ecstasy-naive polydrug controls, including cannabis users, ecstasy users showed lower performance levels with regard to learning and memory (Bolla, et al., 1998; Parrott, et al., 1998; McCann, et al., 1999; Morgan, 1999; Gouzoulis-Mayfrank, et al., 2000; Croft, et al., 2001; Fox, et al., 2001a; Zakzanis and Young, 2001; McCardle, et al., 2004; Yip and Lee, 2005). Reaction time measures typically show no differences between ecstasy users and nonusers, although poorer performance in more complex attention tasks has also been reported (McCann, et al., 1998; GouzoulisMayfrank, et al., 2000; Fox, et al., 2001b; Zakzanis, et al., 2002).

Typically, ecstasy consumers show additional consumption of cannabis (von Sydow, et al., 2002). Thus, cannabis use is an important confounding factor in studying the effects of ecstasy use (Dafters, et al., 2004). Regular heavy cannabis users have been reported to show deficits in memory, learning and attention performance, as well as impairments in reaction time measures (Solowij, 1998; Pope, et al., 2001; Solowij, et al., 2002; Dafters, et al., 2004). Although some of these cannabis-related decrements may be attributable to subacute effects of recent cannabis consumption that cease with continued abstinence (Pope, et al., 2001), there may be more long-lasting effects on brain function and cognition. In a meta-analytic study of longterm cannabis consequences, Grant, et al. (2003) reported slight impairments only in memory and learning domain. For simple reaction time measures or attentional tasks, these authors did not find systematic decrements of function.

As with ecstasy, cannabis use has been associated with an increased incidence of psychiatric disorders. Some authors (e.g., Croft, et al., 2001) have argued that the apparent cognitive and psychiatric effects of ecstasy may, at least to some degree, be caused by concomitant cannabis 
misuse. However, empirical data concerning this question are still inconclusive (GouzoulisMayfrank and Daumann, 2006).

Most users of illegal substances also drink alcohol. Previous research studies primarily investigated the cognitive sequelae of chronic and severe alcohol abuse, focussing on sober alcoholdependent subjects, recruited from substance abuse treatment programs. Chronic, neurotoxic effects of heavy drinking seem to result in functional impairments and atrophic changes in several regions of the cerebral cortex, especially in the frontal lobes, which cause impairments of executive functioning and memory (e.g., Dao-Castellana, et al., 1998). However, the treatment-seeking, alcohol-dependent subjects constitute only a minor portion of the alcohol-consuming population (Meyerhoff, et al., 2005). Compared with clinical populations recruited from treatment centres, much less is known about the level of cognitive function in socially functioning moderate- or heavydrinking populations. It has been argued that there may be a continuum of detrimental effects of alcohol on brain function and cognition (Parsons, 1998), although systematically trends may only become apparent beyond some threshold consumption level of heavy drinking (Parsons and Nixon, 1998).

Additionally, these subtle deficits may be more detectable with some measurement techniques than with others. Neurophysiologic measures suggest a somewhat higher sensitivity than common neuropsychological measurements do (Meyerhoff, et al., 2005).

Little is known about the cognitive sequelae of substance abuse in subjects with moderate levels of drug use. The present study was designed to investigate the question of whether moderate use of ecstasy and cannabis in a population-based sample is associated with reduced performance in memory, verbal learning and complex attentional tasks, as suggested by research in heavy-consuming populations. The participants were not informed about the aim of the present study because this information seems to be a potential contributing factor to self-reported adverse effects of ecstasy use (Cole, et al., 2006).

\section{Methods and materials}

\section{Subjects}

Subjects were recruited from a population-based epidemiological sample investigated in the 'Early Developmental Stages of Psychopathology' (EDSP) study. The EDSP study is a longitudinal study conducted by the Max Planck Institute for Psychiatry in Munich, Germany. From its beginning in 1994, this epidemiological assessment set out to investigate the health of adolescents and young adults. Participants in the EDSP study were interviewed up to four times with a number of substance use and psychiatric questionnaires, including the Munich Composite International Diagnostic Interview (M-CIDI, Pfister and Wittchen, 1995; DIA-X, Wittchen and Pfister, 1997). For further description of the EDSP study, see Lieb, et al. (2000, 2002). A nested case-control design was used. On the basis of the drug history collected in the M-CIDI interviews, subjects were subsampled for additional assessments.

The goal was to obtain a subsample consisting of nearly equal numbers of alcohol, cannabis and ecstasy users, as well as nonusers. Subjects with a history of any ecstasy use were recruited. Furthermore, we recruited participants with a history of cannabis use, which was defined as more than five lifetime occasions. None of them had, at any time, a history of ecstasy, heroin or cocaine use. A third user group consisted of subjects who had not consumed any psychoactive substances, except alcohol. These subjects had to have a lifetime prevalence of consuming alcohol on a harmful basis, as defined by an alcohol index with a minimum of 
seven drinks for six or more months on a single occasion. The only additional drug experiences allowed was a sampling of cannabis, which was defined as no more than five lifetime uses of cannabis. Sampling of cannabis use reported in adults is highly prevalent but is not associated with an increased risk of use of illegal substances (Schütz, et al., 1994). The last portion of the sample consisted of participants who had never taken any kind of psychoactive substance and had no history of harmful alcohol consumption.

Exclusionary criteria for this sample were intravenous drug use and use of cocaine or heroin. Because neurocognitive functions were assessed, subjects with a medical history of brain diseases or injuries were excluded as well as subjects showing signs of mental retardation or psychotic disorders, which could have diminished cognitive performance. Furthermore, subjects with urine samples suggestive of recent drug abuse (e.g., cannabis $>150 \mathrm{ng} / \mathrm{mL}$ ) or signs of depressed mood (see below) were excluded.

After conducting the most recent EDSP interview, we asked 1652 participants to take part in the present study. Of those asked, 701 subjects gave their consent when contacted by staff members of the current investigation, 359 were called by phone and 57 denied participation because of lack of time. The assessment was not completed by 12 individuals. Because of a Beck Depression Inventory (BDI) score exceeding 18 points, three subjects were excluded. Positive urine screening results led to the exclusion of three individuals.

Data attained from 284 subjects were assessed and analysed. Participants were paid for their time and effort $(15 € / \mathrm{h})$. Written informed consent to participate in a study assessing cognitive functioning was obtained from all subjects. The research protocol was approved by the ethics committee (internal review board) of the Medical Faculty of Ludwig-Maximilians University (LMU) of Munich, Germany.

\section{Procedure}

Subjects were instructed not to take any drugs or alcohol for at least 1 week before the test session. This may have a detrimental influence on cognitive performance because the aim of this study was to assess the optimal performance level of participants. Smoking was allowed to avoid disturbances caused by withdrawal.

All participants underwent the same procedure. Assessment consisted of a single session, lasting about $3 \mathrm{~h}$. A testing battery was conducted in two units, with a short break in between. During the break, a urine probe was taken to confirm abstinence and then analysed using standardised methods by the laboratory at LMU. The probe was tested for cocaine, opiates, methadone, cannabis, LSD, amphetamines and barbiturates. Every session was conducted double blind. Neuropsychological assessment included diverse tests of memory and attention. Tests of executive function and working memory will be reported separately (Piechatzek, et al., submitted). Subjects received feedback about their test results at the end of the session. In addition, the Alcohol, Smoking and Substance Involvement Screening Test (ASSIST) was administered (WHO ASSIST Working Group, 2002). If substance use was recorded to be problematic, a short feedback-based intervention, which involved applying motivational interviewing techniques (Rollnick and Bell, 1991), was administered after the neuropsychological testing.

\section{Drug-related variables}


All participants were interviewed extensively regarding their lifetime substance use. The questions are part of the EDSP interview (M-CIDI, Pfister and Wittchen, 1995; DIA-X, Wittchen and Pfister, 1997). Questions included in the sections investigating alcohol and drug use were based on the Diagnostic and Statistical Manual of Mental Disorders, fourth edition (DSM-IV) (American Psychiatric Association, 1994) and the International Statistical Classification of Diseases, 10th revision (ICD-10) (World Health Organisation, 1993) criteria. Some example questions asked on the use of different substances (cannabis, in the examples presented here) are as follows:

- Did you ever use cannabis in your life? If yes, when did you start using the substance?

- Have you stopped using cannabis?

- On how many occasions did you ever use this substance?

Self-reported frequencies were sampled in categories to assess lifetime use (see Table 3).

Assessment of current psychiatric symptoms

BDI (Beck, et al., 1961; German version from Hautzinger, et al., 1994); state-trait anxiety inventory (STAISTAISTAISTAI: Spielberger, 1983; German version, Laux, et al., 1981)

To rule out current psychiatric symptoms as a possible factor causing cognitive deficits, participants completed the BDI and the STAI. The BDI is a 21-item self-report rating inventory measuring characteristic attitudes and symptoms of depression. The STAI consists of 20 items assessing state anxiety and another 20 items assessing trait anxiety.

Estimation of intelligence level

Multiple choice vocabulary test (MWTMWTMWTMWT: Lehrl, et al., 1995; German version (MWT-B) from Lehrl, 1999)

The MWT-B test was performed to assess the intelligence level of the participants included in this study. This test requires participants to select one of five alternative phrases and to mark the only alternative that actually exists in the German language. The test is regularly used for an estimation of IQ because there is a good correlation with general intelligence measures (Lehrl, 1999).

Memory and verbal learning

Logical memory (LM) subtest from the wechsler memory scalerevised (WMS-R: Wechsler, 1987; German version from Härting, et al., 2003)

Using Wechsler's standard instructions for the LM subtest, two stories were presented orally to subjects, each one followed by an immediate free recall trial. Free recall of both stories was again tested after a delay of $30 \mathrm{~min}$. The immediate score reflects the amount of information that subjects can recall immediately after hearing the stories. The delayed score reflects the amount of information from the two stories that a subject can recall after a 30 -min delay.

Rey Auditory-Verbal Learning Test (RAVLTRAVLTRAVLTRAVLT: Rey, 1958; Lezak, 1976, 1983; German version from Heubrock, 1991) 
A 15-word recall list (List A) was presented five times. Subjects were requested to recall as many of the words as possible immediately following each presentation (Trials 1-5). All responses were noted for subsequent scoring. No time limit was given, and participants were allowed to recall all the words in arbitrary order. After Trial 5, a new list of 15 words (List B) was presented, and recall was requested immediately following the presentation. After the List B trial, participants again recalled List A, but without previous presentation (Trial 6).

After a 30-min interval, participants recalled List A without previous information (Trial 7). To test recognition memory, a written list with 50 words was presented. The list contained the words from List A, the words from List B and an additional 20 words that were phonemically and/or semantically similar to the words in Lists A and B. The participants were instructed to mark the 15 words from List A.

Rey-Osterrieth Complex Figure Test (CFTCFTCFTCFT: Rey, 1941; Osterrieth, 1944)

The CFT reflects the visuo-constructive abilities for the copy part and the nonverbal memory abilities for the delayed recall part. First, the participants were required to copy an abstract geometrical figure while it is in view (Copy trial). The time needed to finish the copy and the qualities of the drawing were recorded, and points were assigned for accuracy and placement of each element in the overall design. After a 30-min delay, and without previous information, participants were asked to reproduce the geometrical figure from memory. The number of details remembered after a 30-min delay was used as an indicator for delayed visual memory recall.

\section{Attention}

A broad range of attentional measures exists; however, these attentional tasks have not been systematically discussed within a theoretical framework of attentional subsystems. As with memory, a considerable amount of evidence indicates the existence of different attentional subsystems that seem to be neuroanatomically and neuropharmacologically dissociable to a certain degree (van Zomeren and Brouwer, 1994; Raz and Buhle, 2006). It has also been argued that classical neuropsychological paradigms may be relatively insensitive to performance decrements induced by chronic cannabis abuse (Solowij, 1998).

The current test selection is based on a multidimensional attention model devised by van Zomeren and Brouwer (1994). Their model broadly distinguishes between different aspects of attention, which include the following: 1) intensity, as tapped by alertness (tonic alertness and phasic alertness) and vigilance tests; 2) selectivity, as exemplified by the ability to focus attention on specific stimuli (selective attention); 3) the ability to distribute attentional capacity over several information sources (divided attention) and 4) the ability to change the focus of attention deliberately (flexibility).

Test for attentional performance (TAP, Version 1.7: Zimmermann and Fimm, 2002)

This test consists of a battery of attentional subtests based on reaction time. Subjects were instructed to perform the tasks as quickly as possible while maintaining a high level of accuracy. Each of the tests was introduced with a number of test trials to ensure comprehension of the task demands. For each task, reaction time measures (mean of the correct reactions), the number of errors (false reactions) and the number of omissions (no reactions) were recorded.

TAP - alertness 
A simple reaction time task measures response readiness to a simple visual target (a cross of about $1.2 \times 1.8 \mathrm{~cm}$ ) appearing on a computer screen, which is either preceded (phasic alertness) or not preceded (tonic alertness) by a warning acoustic signal. The tonic alertness condition measures an intrinsic alertness, indicating cognitive control of alertness in the absence of an external cue, whereas phasic alertness relies on facilitating external cues. The test was carried out via an ABBA design (A: block of trials without an acoustic warning signal; B: block of trials with an acoustic warning signal), with 20 stimuli per condition. For the final analysis, the tonic and the phasic parts of the attention measurements were separated.

TAP - incompatibility

Arrows were briefly presented on the left or the right side of a central fixation point in a random manner. The arrows could point to either the right or the left side. Subjects had to respond to the direction of the arrow as quickly as possible by pressing a complementary response key, with a left-hand key corresponding to arrows pointing to the left, and a righthand key corresponding to arrows pointing to the right. Subjects had to suppress interfering tendencies to orient to the side of the presentation. A total of 57 trials were presented.

TAP - flexibility

This task assesses the ability to shift the focus of attention flexibly between stimulus dimensions. Two competing stimuli (one digit and one letter; each $2.0 \times 2.0 \mathrm{~cm}$ ) were presented simultaneously, one on the left and one on the right side of the screen. Subjects had to indicate the position of a current target stimulus (digit or letter) by pressing a corresponding left-hand or right-hand response button. The target stimulus alternates from trial to trial so that subjects had to shift the focus of attention continuously. Depending on the position of the stimuli, the change of target stimulus could be associated with an alternation of the side of the correct reaction or the response hand could remain the same. The latter cases were more complicated, as indicated by slower average reaction times and a higher number of errors. For data analysis, results were separated into trials with hand changing (critical stimuli was not on the same side as in the previous trial) and trials without hand changing (critical stimuli was on the same side as in the previous trial). A total of 100 trials were presented.

TAP - divided attention

This dual task requires attention to visual and acoustic stimuli presented simultaneously. In the visual task, random spatial arrangements of crosses appeared on the screen (of about $9.5 \times$ $11.0 \mathrm{~cm}$ ), and subjects had to react as quickly as possible when four of these crosses formed a square. In the acoustic domain, which was presented in parallel, participants had to detect irregularities within an otherwise alternating sequence of high and low tones (i.e., successions of two high or two low tones). Results for reaction time and error measures of the visual and acoustic domains were separated.

TAP - vigilance

Two small rectangles (of about $1.2 \times 2.4 \mathrm{~cm}$ ), one situated on top of the other, were presented in the centre of the computer screen. The rectangles were filled alternately with a pattern. Subjects were requested to press a response key when the pattern filled the same rectangle twice in succession. The time intervals between these target stimuli were irregular, and the frequency of their appearance was low. The duration of the test was $15 \mathrm{~min}$. A total of about 
600 stimuli were presented. For data analyses, the whole duration of the task was separated into three parts (part one: 1-5 min; part two: 6-10 min; part three: 11-15 min).

\section{Self-reported cognitive deficits}

The cognitive failures questionnaire (CFQCFQCFQCFQ: Broadbent, et al., 1982; German version from Klumb, 1995)

To complement laboratory measures of attentional and memory function with subjective data, the CFQ was conducted. The German version of the CFQ is a 32-item self-report inventory that inquires about a person's failures in attention, memory, perception and motor function over the past 6 months (e.g., 'Do you bump into people?' 'Do you find that you forget appointments?'). The response format uses a 5-point scale ( $0=$ never, $4=$ always $)$. The score is a weighted sum of all items.

\section{Statistical analysis}

All data were analysed using the Statistical Package for the Social Sciences version 13.0 for Windows (SPSS, Inc. Chicago, Illinois, USA). Multiple linear regression models were used to analyse the relationships between predictors and dependent measures. The model included variables for the lifetime use (occasions) of the three substance classes (ecstasy, cannabis and alcohol), as well as the control variables (sex, verbal IQ and age) as predictors. Using a hierarchical approach, the background variables [sex, age (Davies, et al., 1992) and intelligence (Anderson, 1992)] were included in the first step. The drug use variables could then be included in the second step so that the significance of the increment in the R2 value could be evaluated.

To conduct regression analyses, original categorical data of ecstasy and cannabis use were transformed into metric data by using the midpoint of each category. For the category of more than 365 times of cannabis consumption, it was not possible to transform data by using the midpoint of the category. To eliminate bias caused by extreme values, the trimmed mean was used to estimate the midpoint of the highest consumption categories. Because the alcohol use variable was already assessed in metric, no transformation was needed.

First, the correlations between predictors were calculated. To prevent interpretation problems because of multicollinearity, a forward approach for multiple linear regression analysis was chosen. The inclusion criterion was $\mathrm{P}<5 \%$, and the exclusion criterion was $\mathrm{P}>10 \%$.

The distribution of the raw data of lifetime use for the three substance classes was skewed to the right. A logarithmic transformation $(\log 10)$ was performed to reduce the violation of the normal distribution. The logarithmic function is not defined for zero. To complete the analysis, ' 1 ' was added to the raw data before the logarithmic transformation.

Effect sizes were estimated based on conventions put forth by Cohen (1988), suggesting 'small' effects with $\mathrm{R}^{2} \mathrm{adj} \geq 0.02$, 'medium' effects with $\mathrm{R}^{2} \mathrm{adj} \geq 0.13$ and 'large' effects with $\mathrm{R}^{2} \mathrm{adj} \geq 0.26$.

\section{Demographics and current psychiatric symptoms}

A total of 284 subjects were tested, 181 men and 103 women. Frequencies for sex are described in Table 12. The mean age was 25.83 years $(\mathrm{SD}=3.08)$, with a range of $22-34$ 
years. More than 75\% (214 subjects) of the subjects had a university-entrance diploma or an even higher level of education. Table 2 presents the scores of the IQ, depression and anxiety measures.

\section{Substance use}

The lifetime frequencies of ecstasy and cannabis consumption are presented in Table 3. Ecstasy consumption among the subjects was predominantly low, with only several occasions of ecstasy intake. Only nine subjects used ecstasy on more than 50 occasions in their lifetime. Of the tested sample, $43 \%$ never used cannabis, more than $38 \%$ used it on fewer than 365 occasions in their lifetime and up to $18 \%$ used cannabis more than 365 times. The categories are not identical to those described in publications investigating the full EDSP samples.

The alcohol indices (estimate of overall alcohol use) were derived from the mean amount of alcohol and from the frequency of alcohol intake during the period of heaviest lifetime use. To compare the different effects of alcohol on women and men, the amount consumed by women was multiplied by a factor of 1.5 (Uhl, et al., 2001). The mean of the tested population was $28.3 \mathrm{~g} /$ day, with an SD of $34.8 \mathrm{~g}(0-270 \mathrm{~g} /$ day $)$. This index value is most likely an overestimation of the real amount because the estimations are based on the heaviest reported period in lifetime use. Because the other substances are not fluid based and similar sex effects have not been established, we refrained from similar adaptations for the other substances.

\section{Results}

Attributing specific effects to specific substances is a problem because multiple substance use is the rule. To account for multiple substance use and to adjust for other major confounders, the analysis is based on linear regression models.

\section{Predictor variables and correlations}

The amounts of ecstasy, cannabis and alcohol use were defined as predictor variables. Sex, age and IQ were included as further control variables or background variables. The intercorrelations of the mentioned variables are shown in Table 4. A correlation matrix with correlations for the predictors against each of the dependent variables, means and standard deviations for each variable are shown in Table 11 and Table 13.

\section{Background variables}

In 11 of the 24 regression models, sex was a significant predictor. As a predictor, IQ was significant in 10 of the 24 regression models. Age was a significant predictor in 7 of the 24 regression analysis models $(\alpha=0.05)$ (for details, see Tables 5-10).

\section{Memory and verbal learning}

\section{Logical memory}

As shown in Table 5, lifetime cannabis consumption was a significant predictor of performance for the immediate recall $(\mathrm{R} 2$ (change) $=0.019 ; \mathrm{df}=1 ; \mathrm{P}<0.016)$ and the delayed recall $(\mathrm{R} 2$ (change) $=0.020 ; \mathrm{df}=1 ; \mathrm{P}<0.014)$ of $\mathrm{LM}$. 
The linear regression results for the RAVLT are shown in Table 6. For the first delayed recall of List A (List A, 6), ecstasy consumption was a significant predictor of performance (R2 (change) $=0.025 ; \mathrm{df}=1 ; \mathrm{P}<0.005)$.

Rey-Osterrieth Complex Figure Test

Results for time needed and accuracy data are shown in Table 7. For the CFT copy task, ecstasy consumption was a significant predictor of performance $(\mathrm{R} 2$ (change) $=0.014$; $\mathrm{df}=1$; $\mathrm{P}<0.048)$.

\section{Attention}

Reaction time measures

Results of the forward linear regression model for the median reaction time measures in tonic and phasic alertness, selective attention, flexibility, divided attention and vigilance are shown in Table 8 . None of the tested substances reached the level of significance.

\section{Error measures}

The results of the linear regression models for the number of errors and omissions in the tonic and phasic alertness, selective attention, flexibility, divided attention and vigilance tasks are shown in Table 9. For the number of omissions in the tonic alertness task (R2 (change) $=$ $0.028 ; \mathrm{df}=1 ; \mathrm{P}<0.005)$, cannabis was the significant predictor. In the phasic alertness task $(\mathrm{R} 2$ (change) $=0.023 ; \mathrm{df}=1 ; \mathrm{P}<0.011$, the selective attention task $(\mathrm{R} 2($ change $)=0.030 ; \mathrm{df}$ $=1 ; \mathrm{P}<0.004$ and the vigilance task score $(\mathrm{R} 2$ (change) $=0.030 ; \mathrm{df}=1 ; \mathrm{P}<0.004)$, ecstasy was the significant predictor.

\section{Cognitive Failures}

Questionnaire Cannabis was the significant predictor of the outcome in the CFQ score (R2 (change) $=0.054 ; \mathrm{df}=1 ; \mathrm{P}<0.001)$. A high amount of cannabis use was predictive of more self-experienced failures in everyday life. Further details are described in Table 10.

\section{Discussion}

The aim of the present investigation was to assess the memory and attentional performance of subjects with varying degrees of drug-use experience. Participants were selected from a community-based representative sample being investigated for a large-scale epidemiological study. This subsample consisted of 284 subjects, ranging from 22 to 34 years, with different levels of drug abuse, as indicated by data from previous assessments. In general, the subjects reported moderate levels of drug use experience, with only a limited number of participants reporting regular and extensive use of illicit substances. Published studies examining cognition in substance users have regularly relied on self-referred participants with more extensive drug-use histories, thus focussing on high-risk populations (Block and Ghoneim, 1993; Fletcher, et al., 1996; Parrott, et al., 1998; Schifano, et al., 1998; McCann, et al., 1999; Morgan, 1999; Rodgers, 2000; Croft, et al., 2001; Pope, et al., 2001; Gruber, et al., 2003; McCardle, et al., 2004; Yip and Lee, 2005). On the contrary, data obtained from 
epidemiological samples may create a picture that more closely resembles a population-based picture of possible detrimental effects associated with substance abuse.

Participants were informed that cognitive performance in young adults would be assessed. Furthermore, they knew that they would be paid for their time and provided with short feedback about their performance at the end of testing. On the contrary to many previous studies, subjects had no a priori knowledge that drug use was the critical condition for their selection into the present subsample. In addition, the testing psychologists were blind to the subjects' drug-use history. Thus, test results should be less confounded by subjective expectations and sample biases, which have influenced studies reported to date.

Even though subjects were subsampled from a regionally representative sample of young adults, demographic data concerning educational background and estimations of intelligence indicate that the sample showed comparably high levels of cognitive functioning. It is quite possible that higher levels of cognitive function are helpful in compensating for the detrimental effects of factors that reduce brain functions, as suggested by concepts of cerebral reserve capacity ('functional reserve': Fein and Di Sclafani, 2004). In fact, several of the parameters showed an additional predictive relationship with IQ. Therefore, the associations between cognitive function and drug abuse variables determined in this population possibly represent the lower boundaries of the empirical associations that may be found in more heterogeneous populations, with respect to levels of cognitive function.

\section{Memory and verbal learning}

Reduced ability to recall a short passage of prose immediately and after a delay was associated with increasing lifetime use of cannabis. Increasing cannabis lifetime use was also associated with lower scores for the immediate, as well as delayed, recall. These findings are in line with the results of a meta-analytic study showing the small effects of cannabis use on memory functions (Grant, et al., 2003).

When the competencies of repeated list learning were assessed, only the results obtained for the recall of List A after the interfering List B were associated with ecstasy use. A possible explanation may be the different form of task presentation. Whereas the RAVLT task was presented five times, the LM task was presented only once. In terms of visual memory performance, no relation between substance use history and nonverbal memory was found.

Lower scores in memory and verbal learning performance are the most common findings in heavy users of illegal substances. Because the assessed sample comprised young and welleducated subjects with high intelligence levels, drug use was not likely to cause massive cognitive deficits in these subjects. Thus, the small effect sizes are not surprising. This emerging pattern of reduced memory and verbal learning performance associated with drug use is consistent with a number of studies showing memory impairment to be the most consistent deficit associated with ecstasy and cannabis use (Verbaten, 2003; Dafters, 2006; Fisk, et al., 2006). Ecstasy use among subjects in this study was almost always combined with cannabis use, as has been the case in previous studies.

\section{Attention}

In three of five aspects of attention assessed, an association between drug use and error frequency was detected. Small effects were found even for aspects of tonic and phasic alertness, selective attention and vigilance. All effects were in the same direction. An 
increasing amount of substance use was associated with higher numbers of errors or omissions. No association was detected between reaction time measures and substance use. In general, reaction time was associated with socio-demographic factors, such as sex and age.

Some evidence for slower reaction times and more errors has been reported in the literature, specifically for complex attentional tasks (McCann, et al., 1998; Gouzoulis-Mayfrank, et al., 2000; Fox, et al., 2001a,b). Average reaction times in combination with a higher incidence of errors may be interpreted as a higher frequency of lapses of attention (i.e., short-term losses of attentional control). These participants may experience more difficulties exerting deliberate control over their level of attention (Raz and Buhle, 2006). Such lapses of attention may become more apparent under sustained attention conditions.

\section{Subjective memory complaints}

In this study, cannabis use was associated with higher scores in self-reported cognitive deficits in everyday life, whereas ecstasy use failed to become a significant predictor. In an Internet survey, Rodgers, et al. (2001) showed that cannabis use was associated with subjective short-term memory problems, whereas ecstasy use was more related to subjective long-term memory problems. In an earlier study, Rodgers (2000) reported that ecstasy use was not associated with self-reported deficits on the CFQ. Given the quite low lifetime doses of the previous ecstasy consumers, these cognitive findings would not yet have an impact on daily life activities. The cognitive failure reported by cannabis users may be attributed to the prolonged pharmacological effects of cannabis.

In summary, we found ecstasy and cannabis use to be associated with results of the verbal memory tasks. List learning was not associated with drug use; however, the capacity to reproduce a learned list after an interfering list seemed to be lower in relation to ecstasy use. The error frequencies in three of five attentional tasks were also associated with the use of ecstasy and cannabis. Reaction time measures for different tasks were unrelated to substance use. Alcohol use did not show any relation to test results.

\section{Limitations}

There are some limitations that have to be considered when interpreting the findings of this study. A causal interpretation of the correlative relationships is hampered by the existence of potential residual confounders. The nature of this design also makes it impossible to make an inference on the temporal relationship between cognitive performance and drug abuse.

With 24 regressions analysed, the family-wise error rate for each predictor is approximately 0.70 . An adjusted $\alpha$-value of 0.002 would reduce the family-wise error rate to roughly 0.05 . This indicates that findings might be chance findings, and need to be replicated, before solid conclusions can be drawn.

As previously pointed out by other authors (Schuster, et al., 1998; Gouzoulis-Mayfrank and Daumann, 2006), it is difficult to separate the effects of the different substances used by the participants. Given that distinct groups are not available (and if available, these groups would not be considered representative), we used regression analysis to separate statistically the distinct effects.

Neuropsychological testing was developed to assess differences after brain lesions. It remains open as to how useful these tests are in detecting subtle deficits, such as the ones mentioned in 
this study. The purpose of this project was to explore the possible effects of moderate substance use in young adults in a population-based sample.

As already mentioned, higher-educated subjects were more likely to participate in that study than less-educated subjects. Participants of this study have high intelligence levels. These subjects may also have good compensation strategies that facilitate cognitive outcome, thus masking the detrimental effects of drug abuse that may be detectable in less-educated subjects.

Intensity of use and/or time since last substance use was not systematically manipulated in this study and could be relevant factors for cognitive outcome, specifically because studies have reported persistent effects of cannabis during initial abstinence. By interviewing patients, using alcohol breathalysers and performing urine analysis, we made sure that none of the participants was intoxicated. Subjects were allowed to smoke cigarettes during the time before the test session. In this study, we, thus, adopted the reported approach to tobacco smoking, smoking history was not quantified.

Despite these limitations, the results provide evidence that even limited illegal drug use may have a subtle influence on cognition in otherwise healthy and well-educated young people. Further investigations are necessary to increase our knowledge of the consequences of substance use in young users who are not seeking treatment. Longitudinal investigations would be most helpful in verifying the existence of a causal relationship between substance abuse and decrements in cognitive function, and in ruling out premorbid factors as possible explanations.

\section{Acknowledgements}

We would like to thank the federal grant of the Federal Ministry of Education and Research for supporting the study.

\section{References}

American Psychiatric Association (1994) Diagnostic and Statistical Manual of Mental Disorders, DSM-IV, fourth ed. Washington, D.C: American Psychiatric Association.

Anderson, M (1992) Intelligence. In: Smith, AP, Jones, DM (eds), Handbook of Human Performance, State and Trait, vol. 3. London: Academic Press, pp. 1-24.

Beck, AT, Ward, CH, Mendelson, M, Mock, J, Erbaugh, J (1961) An inventory for measuring depression. Arch Gen Psychiatry 4: 561-571.

Block, RI, Ghoneim, MM (1993) Effects of chronic marijuana use on human cognition.

Psychopharmacology 110: 219-228.

Bolla, KI, McCann, UD, Ricaurte, GA (1998) Memory impairment in abstinent MDMA ("Ecstasy") users. Neurology 51: 1532-1537.

Broadbent, DE, Cooper, PF, Fitzgerald, P, Parkes, KR (1982) The Cognitive Failures Questionnaire (CFQ) and its correlates. Br J Clin Psychol 21: 1-16.

Cohen, J (1988) Statistical Power Analysis for the Behavioural Sciences, second ed. Hillsdale, NJ:

Erlbaum.

Cole, JC, Michailidou, K, Jerome, L, Sumnall, HR (2006) The effects of stereotype threat on cognitive function in ecstasy users. J Psychopharmacol 20: 518-525.

Croft, RJ, Mackay, AJ, Mills, ATD, Gruzelier, JGH (2001) The relative contributions of Ecstasy and Cannabis to cognitive impairment. Psychopharmacology 153: 373-379.

Dafters, RI (2006) Chronic ecstasy (MDMA) use is associated with deficits in task-switching but not inhibition or memory updating executive functions. Alcohol Depend 83: 181-184. 
Dafters, RI, Hoshi, R, Talbot, AC (2004) Contribution of cannabis and MDMA ("Ecstasy") to cognitive changes in long-term polydrug users. Psychopharmacology 173: 405-410.

Dao-Castellana, MH, Samson, Y, Legault, F, Martinot, JL, Aubin, HJ, Crouzel, C, Feldman, L, Barrucand, D, Rancurel, G, Feline, A, Syrota, A (1998) Frontal dysfunction in neurologically normal chronic alcoholic subjects: metabolic and neuropsychological findings. Psychol Med 28: 1039-1048. Davies, DR, Taylor, A, Dorn, L (1992) Aging and human performance. In: Smith, AP, Jones, DM (eds), Handbook of Human Performance, State and Trait, vol. 3. London: Academic Press, pp. 25-62. Dumont, GJH, Verkes, RJ (2006) A review of acute effects of 3,4-methylenedioxymethamphetamine in healthy volunteers. J Psychopharmacol 20: 176-187.

Fein, G, Di Sclafani, V (2004) Cerebral reserve capacity: implications for alcohol and drug abuse. Alcohol 32: 63-67.

Fisk, JE, Montgomery, C, Wareing, M, Murphy, PN (2006) The effects of concurrent cannabis use among ecstasy users: neuroprotective or neurotoxic? Hum Psychopharmacol Clin Exp 21:355-366. Fletcher, JM, Page, JB, Francis, DJ, Copeland, K, Naus, MJ, Davis, CM, et al. (1996) Cognitive correlates of long-term Cannabis use in Costa Rican men. Arch Gen Psychiatry 53: 1051-1057. Fox, HC, Parrott, AC, Turner, JJ (2001a) Ecstasy use: cognitive deficits related to dosage rather than self-reported problematic use of the drug. J Psychopharmacol 1: 273-281.

Fox, HC, Toplis, AS, Turner, JJ, Parrott, AC (2001b) Auditory verbal learning in drug-free Ecstasy poly-drug users. Hum Psychopharmacol Clin Exp 16: 613-618.

Gouzoulis-Mayfrank, E, Daumann, J (2006) The confounding problem of poly-drug use in recreational ecstasy/MDMA users: a brief overview. J Psychopharmacol 20: 188-193.

Gouzoulis-Mayfrank, E, Daumann, J, Tuchtenhagen, F, Pelz, S, Becker, S, Kunert, H-J, et al. (2000) Impaired cognitive performance in drug-free recreational Ecstasy (MDMA) users. J Neurol Neurosurg Psychiatry 70: 95-100.

Grant, I, Gonzalez, R, Carey, LC, Natarajan, L, Wolfson, T (2003) Non-acute (residual) neurocognitive effects of cannabis: a metaanalytic study. J Int Neuropsychol Soc 9: 679-689. Green, AR, Mechan, AO, Elliott, JM, O’Shea, E, Colado, MI (2003) The pharmacology and clinical pharmacology of 3,4-methylenedioxymethamphetamine (MDMA, "Ecstasy"). Pharmacol Rev 55: 463-508.

Gruber, AJ, Pope, HG, Hudson, JI, Yurgelun-Todd, D (2003) Attributes of long-term heavy cannabis users: a case-control study. Psychol Med 33: 1415-1422.

Härting, C, Markowitsch, HJ, Neufeld, H, Calabrese, P, Deisinger, K, Kessler, J (2003) Wechsler Gedächtnis Test - Revidierte Fassung. Deutsche Adaptation der revidierten Fassung der Wechsler Memory Scale. Berlin: Verlag Hans Huber.

Hautzinger, M, Bailer, M, Worall, H, Keller, F (1994) Beck-Depressions-Inventar (BDI). Bearbeitung der deutschen Ausgabe. Testhandbuch. Berlin: Verlag Hans Huber.

Heubrock, D (1991) Der Auditiv-Verbale Lerntest (AVLT) in der klinischen und experimentellen Neuropsychologie. Durchführung, Auswertung und Forschungsergebnisse. Zeitschrift für Differentielle und Diagnostische Psychologie 13: 161-174.

Klumb, P (1995) Cognitive failures and performance differences: validation studies of a German version of the Cognitive-Failures-Questionnaire. Br J Psychol 88: 29-38.

Laux, L, Glanzmann, P, Schaffner, P, Spielberger, CD (1981) Das State-Trait-Angst-Inventar. Theoretische Grandlagen und Handanweisung. Weinheim: Beltz Test GmbH.

Lehrl, S (1999) Mehrfachwahl-Wortschatz-Intelligenztest MWT-B. Manual. 4. überarbeitete Auflage. Balingen: Spitta Verlag.

Lehrl, S, Triebig, G, Fischer, B (1995) Multiple choice vocabulary test MWT as a valid and short test to estimate premorbid intelligence. Acta Neurol Scand 91: 335-345.

Lezak, MD (1976) Neuropsychological Assessment. New York: Oxford University Press.

Lezak, MD (1983) Neuropsychological Assessment, second ed. New York: Oxford University Press. Lieb, R, Isensee, B, von Sydow, K, Wittchen, HU (2000) The Early Developmental Stages of Psychopathology Study (EDSP): a methodological update. Eur Addict Res 6: 170-182.

Lieb, R, Schütz, CG, Pfister, H, von Sydow, K, Wittchen, HU (2002) Mental disorder in Ecstasy users: a prospective-longitudinal investigation. Drug Alcohol Depend 68: 195-207.

McCann, UD, Eligulashvili, V, Ricaurte, GA (2000) ( \pm )3,4-methylenedioxymethamphetamine (MDMA) induced serotonin neurotoxity: Clinical studies. Neuropsychopharmacology 23: 113-126. 
McCann, UD, Mertl, M, Eligulashvili, V, Ricaurte, GA (1999) Cognitive performance in $\pm 3,4$ methylenedioxymethamphetamine (MDMA, "Ecstasy") users: a controlled study.

Psychopharmacology 143: 417-425.

McCann, UD, Szabo, Z, Scheffel, U, Dannals, RF, Ricaurte, GA (1998) Positron emission tomographic evidence of toxic effect of MDMA ("ecstasy") on brain serotonin neurons in human beings. Lancet 352: 1433-1437.

McCardle, K, Luebbers, S, Carter, JD, Croft, RJ, Stough, C (2004) Chronic MDMA (ecstasy) use, cognition and mood. Psychopharmacology 173: 434-439.

Meyerhoff, DJ, Bode, C, Nixon, SJ, de Bruin, EA, Bode, CJ, Seitz, HK (2005) Health risk of chronic moderate and heavy alcohol consumption: how much is too much? Alcohol Clin Exp Res 29:13341340.

Morgan, MJ (1999) Memory deficits associated with recreational use of "Ecstasy" (MDMA).

Psychopharmacology 141: 30-36.

Morton, J (2005) Ecstasy: pharmacology and neurotoxicity. Curr Opin Pharmacol 5: 79-86.

Osterrieth, PA (1944) Le test de copie d'une figure complex: contribution à l'étude de la perception et de la mémoire. Arch Psychol 30:286-356.

Parrott, AC, Less, A, Garnham, NJ, Jones, M, Wesness, L (1998) Cognitive performance in recreational users of MDMA of "Ecstasy": evidence for memory deficits. J Psychopharmacol 12:7983.

Parsons, OA (1998) Neurocognitive deficits in alcoholics and social drinkers: a continuum? Alcohol Clin Exp Res 22: 954-961.

Parsons, OA, Nixon, SJ (1998) Cognitive functioning in sober social drinkers: a review of the research since 1986. J Stud Alcohol 59:180-190.

Pfister, H, Wittchen, HU (1995) M-CIDI-Computerprogramm. München: Max-Planck-Institut für Psychiatrie, klinisches Institut.

Piechatzek, M, Indlekofer, F, Daamen, M, Glasmacher, C, Lieb, R, Pfister, H, et al. (submitted)

Executive functions, working memory and impulsivity in a population-based sample of young adults with moderate or rare lifetime use of Ecstasy, Cannabis and Alcohol.

Pope, HG, Gruber, AJ, Hudson, JI, Huestis, MA, Yurgelun-Todd, D (2001) Neuropsychological performance in long-term cannabis users. Arch Gen Psychiatry 58: 909-915.

Raz, A, Buhle, J (2006) Typologies of attentional networks. Nat Rev Neurosci 7: 367-379.

Reneman, L, de Win, ML, van den Brink, W, Booij, J, den Heeten, GJ (2005) Neuroimaging findings with MDMA/ecstasy: technical aspects, conceptual issues and future prospects. J Psychopharmacol 20: $164-175$.

Reneman, L, Lavalaye, J, Schmand, B, de Wolff, FA, van den Brink, W, den Heeten, GJ, Booij, J (2001) Cortical serotonin transporter density and verbal memory in individuals who stopped using 3,4methylenedioxymethamphetamine (MDMA or "ecstasy"). Arch Gen Psychiatry 58: 901-906.

Rey, A (1941) L'examen psychologique dans les cas d'encéphalopathie traumatique. Arch Psychol 28: 286-340. Rey, A (1958) L'examen clinique en psychologie. Paris: Presse Universitaire de France.

Ricaurte, GA, Yuan, J, McCann, UD (2000) \pm 3 ,4-Methylenedioxymethamphetamine ('Ecstasy')induced serotonin neurotoxicity: studies in animals. Neuropsychobiology 42: 5-10.

Rodgers, J (2000) Cognitive performance amongst recreational users of ecstasy. Psychopharmacology 151: 19-24.

Rodgers, J, Buchanan, T, Scholey, AB, Heffernan, TM, Ling, J, Parrott, AC (2001) Differential effects of ecstasy and cannabis on self-reports of memory ability: a web-based study. Hum Psychopharmacol Clin Exp 16: 619-625.

Rogers, RD, Robbins, TW (2001) Investigating the neurocognitive deficits associated with chronic drug misuse. Curr Opin Neurobiol 11: 250-257.

Rollnick, S, Bell, A (1991) Brief motivational interviewing for use by the nonspecialist. In: Miller, WR, Rollnick, S (eds), Motivational Interviewing: Preparing People to Change Addictive Behaviors. New York: Guilford Press.

Schifano, F, Di Furia, L, Forza, G, Minicuci, N, Bricolo, R (1998) MDMA “Ecstasy" consumption in the context of poly-drug abuse: a report on 150 patients. Drug Alcohol Depend 52: 85-90.

Schuster, P, Lieb, R, Lamertz, C, Wittchen, HU (1998) Is the use of ecstasy and hallucinogens increasing? Eur Addict Res 4: 75-82. 
Schütz, CG, Chilcoat, HD, Anthony, JC (1994) The association between sniffing inhalants and injecting drugs. Compr Psychiatry 35: 99-105.

Solowij, N (1998) Cannabis and Cognitive Functioning. Cambridge: Cambridge University Press. Solowij, N, Stephens, RS, Roffman, RA, Babor, T, Kadden, R, Miller, M, et al. (2002) Cognitive functioning of long-term heavy cannabis users seeking treatment. JAMA 287: 1123-1131.

Spielberger, CD (1983) Manual for the State-Trait Anxiety Inventory (STAI). Palo Alto, CA: Consulting Psychologists Press.

Strote, J, Lee, JE, Wechsler, H (2002) Increasing MDMA use among college students: results of a national survey. J Adolesc Health 30:64-72.

Uhl, A, Kopf, N, Springer, A, Eisenbach-Stangl, I, Kobrna, U, Bachmayer, S, et al. (2001) Handbuch Alkohol Österreich Zahlen - Daten - Fakten - Trends; 2. überarbeitete Auflage. Bundesministerium für soziale Sicherheit und Generationen (Hrsg.).

van Zomeren, AH, Brouwer, WH (1994) Clinical Neuropsychology of Attention. New York: Oxford University Press.

Verbaten, MN (2003) Specific memory deficits in ecstasy users? The results of a meta-analysis. Hum Psychopharmacol 18: 281-290.

von Sydow, K, Lieb, R, Pfister, H, Höfler, M, Wittchen, HU (2002) Use, abuse and dependence of ecstasy and related drugs in adolescents and young adults - a transient phenomenon? Results from a longitudinal community study. Drug Alcohol Depend 66: 147-159.

Wechsler, D (1987) WMS-R: Wechsler Memory Scale—Revised (Manual). San Antonio, TX: The Psychological Corporation. WHO ASSIST Working Group (2002) The Alcohol, Smoking and Substance Involvement Screening Test (ASSIST): development, reliability and feasibility. Addiction 97: 1183-1194.

Wittchen, HU, Pfister, H (1997) DIA-X-Interviews: Manual für Screening-Verfahren und Interview; Interviewheft Längsschnittuntersuchung (DIA-X-Lifetime); Ergänzungsheft (DIA-X-Lifetime); Interviewheft Querschnittuntersuchung (DIA-X-12 Monate); Ergänzungsheft (DIA-X-12 Monate); PC Programm zur Durchführung des Interviews (Längs- und Querschnittuntersuchung);

Auswertungsprogramm. Frankfurt: Swets und Zeitlinger.

World Health Organisation (1993) Tenth Revision of the International Classification of Diseases. ICD-10. Geneva: World Health Organisation.

Yip, JT, Lee, TM (2005) Effect of ecstasy use on neuropsychological function: a study in Hong Kong. Psychopharmacology 179:620-628.

Zakzanis, KK, Young, DA (2001) Memory impairment in abstinent MDMA users: a longitudinal investigation. Neurology 56: 966-969.

Zakzanis, KK, Young, DA, Radkhoshnound, NF (2002) Attentional processes in abstinent methylenedioxymethamphetamine (ecstasy) users. Appl Neuropsychol 9: 84-91.

Zimmermann, P, Fimm, B (2002) A test battery for attentional performance. In: Leclercq, M, Zimmermann, P (eds), Applied Neuropsychology of Attention. Theory, Diagnosis and Rehabilitation, pp. 110-151. 